\title{
Finite element simulation of 3-D laser forming by discrete section circle line heating
}

\author{
K. Venkadeshwaran*, S. Das and D. Misra
}

School of Laser Science \& Engineering, Jadavpur University, Kolkata - 700 032, INDIA

"Corresponding Author: e-mail:venkat.slse@gmail.com

\begin{abstract}
Laser forming of sheet metal is the bending process, induced by thermal stress, which is produced in the sheet by laser irradiation. Laser forming of complex shapes requires the study of the effect of various irradiation paths. In this paper the deformation of a circular plate, subjected to a circular irradiation path, is studied through a sequentially coupled thermomechanical elasto-plastic simulation by finite element method. The quality of laser bending in terms of waviness parameters, e.g., waviness average, $R_{a}$, RMS value, $R_{q}$, etc. are reported in detail, with respect to number of sections and number of passes of heating, as well as, shifting of the starting point for irradiation. It is observed that discrete section heating in symmetry with shifting in starting point of irradiation in subsequent passes reduces the undesired waviness, which is caused, otherwise, due to continuous circular heating.
\end{abstract}

Keywords: Laser forming, irradiation pattern, FEM

\section{Introduction}

Laser forming is the process of causing distortion to a metal sheet, subjected to laser irradiation. The path of laser irradiation determines the final shape of the metal sheet. This opens up many possibilities, including forming and shaping of sheet metal without the use of any fixture, stamping dies, or other tooling. Laser forming is a spring-back-free and non contact forming technique. The process requires no hard tooling or external forces, since the bending is achieved by plastic deformation, induced by thermal stresses, resulting from rapid non-linear thermal cycles.

Laser forming has been the subject of interest for many researchers. Vollertsen et al. (1994) investigated the mechanisms of laser forming. Ji and Wu (1998) simulated the temperature distribution during laser forming. Kyrsanidi et al. (2000) developed an analytical model to predict the final deformation of the sheet metal subjected to laser irradiation. And a number of researches followed it up with finding the optimum parameters that would yield maximum bend angle per pass. The edge effects and the effect of number of passes were also studied.

A considerable amount of work has been done in laser forming of sheets by straight line heating for two-dimensional laser forming. However, in order to take the process closer to real life applications, an investigation into other possible scanning patterns becomes a necessity. Hennige (2000) investigated curved bending of circular sectors. Edwardson et al. (2001) studied different scanning strategies to develop a saddle shape from a flat sheet. Chen et al. (2004) and Zhang et al. (2002) studied the laser curve bending of Ti-6Al-4V alloy steel sheet metal and showed that 3-D deformation occurs only on one side of a scanning path, along which, the rigid constraint is relatively lower, and on this side, the sheet is extended and thinned slightly. Ojedaa and Grez (2009) investigated a few other scanning strategies, like zigzag, squared and stepped scan lines. Kim and Na (2003) developed displacement based and angle based algorithms for generating the laser scanning paths and predicting the bending angles for each path. Attempts are being made to generate more complex shapes.

Therefore, for the production of complex spatially curved shapes, irradiation strategies based on curved irradiation paths can be used, alone, or along with the linear irradiation paths. This work attempts to study the deformation pattern of a circular plate, subjected to circular path of irradiation through finite element simulation, with the aim of identifying the deficits of curved irradiation paths and proposing solution for the same. 


\section{Theoretical Background}

2.1 Transient thermal analysis: The transient temperature field, generated during laser forming, is determined, based on the mechanism of heat conduction. The following assumptions are made for the calculation of temperature. The distribution of laser intensity follows the Gaussian mode. Heat conduction within the specimen, free convection and radiation, from the surfaces of the specimen to the surrounding air, are considered. At the same time, the laser forming is being performed under the melting temperature of the material, so that there is no convection problem at the interface of the solid and the liquid, thus phase change and heat generation are neglected.

The governing equation for heat conduction, within the plate, assuming isotropic material, can be expressed as follows:

$\rho c \frac{\partial T(\mathbf{r}, t)}{\partial t}=K \nabla_{r} \cdot\left(\nabla_{r} T\right)$

Where $\rho$ is the material density $(\mathrm{kg} / \mathrm{m} 3), c$ is the specific heat $(\mathrm{J} / \mathrm{kg} 0 \mathrm{C}), K$ is the thermal conductivity $\left(\mathrm{W} / \mathrm{m}{ }^{0} \mathrm{C}\right), T(\mathbf{r}, t)$ is the temperature $(\mathrm{K}), \mathbf{r}$ is the coordinate in the reference configuration, $\mathrm{t}$ is the time (s) and $\nabla_{r}$ is the gradient operator. In the present study, $\mathrm{x}$ - and $\mathrm{y}$ - axes are defined in the plane of the plate and the $\mathrm{z}$-axis is defined normal to the plate.

The convection and radiation boundary conditions are as follows

$q_{\text {conv }}=h\left(T-T_{0}\right)$

$\mathrm{h}$ is the natural convection exchange coefficient (taken as $5 \mathrm{~W} / \mathrm{m}^{2} \mathrm{~K}$ ), $\mathrm{T}_{0}$ surrounding temperature (taken as $300 \mathrm{~K}$ ), $\mathrm{T}$ is the surface temperature

$q_{\text {rad }}=\varepsilon \sigma\left(T-T_{0}\right)^{4}$

where $\varepsilon$ is the emissivity $(0.6)$ and $\sigma$ is the Stefan Boltzmann constant $\left(5.6703 \times 10-8\left(\mathrm{~W} / \mathrm{m}^{2} \mathrm{~K}^{4}\right)\right)$. The convection and radiation boundary conditions have been combined together as

$q_{\text {comb }}=h_{\text {comb }}\left(T-T_{0}\right)$

where $h_{\text {comb }}=h+\varepsilon \sigma\left(T+T_{0}\right)\left(T^{2}+T_{0}^{2}\right)$

Tabulated values of $\mathrm{h}_{\text {comb }}$ at different values of $\mathrm{T}$ are given as temperature dependent heat transfer coefficient.

The moving heat flux, generated by laser beam, is applied on the top surface and is assumed to have a Gaussian distribution, as shown in Fig. 1. The heat flux distribution, I is expressed as

$I=\frac{2 A P}{\pi R^{2}}\left(-\frac{2 r^{2}}{R^{2}}\right)$

where, $A$ is the absorptivity of laser energy, $P$ is the laser power, $R$ is the laser beam radius and $r$ is the distance from the center of the laser beam.

The initial temperature distribution in the entire volume is given by

$T=T_{0}$

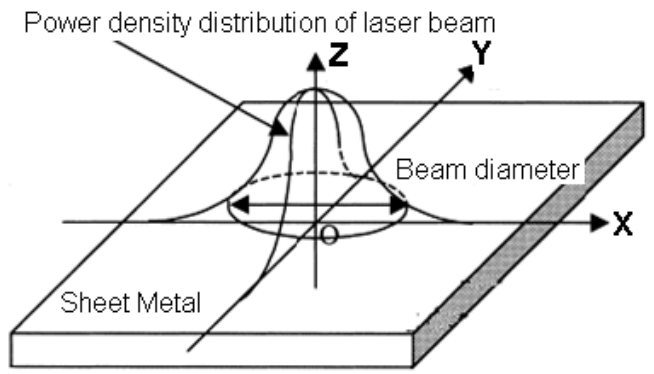

Figure 1. Gaussian heat flux distribution

2.2 Elasto-Plastic analysis: The stress equilibrium equation is given by

$\nabla_{\mathbf{r}} \sigma(\mathbf{r}, t)+\mathbf{b}(\mathbf{r}, t)=0$ in $V_{\mathbf{r}}$

where $\sigma$ is the stress, and $\mathbf{b}$ the body force. The boundary conditions are

$\mathbf{u}(\mathbf{r}, t)=\overline{\mathbf{u}}(\mathbf{r}, t)$ on surface $A_{\mathbf{r}}^{u}$,

$\boldsymbol{\sigma}(\mathbf{r}, t) \cdot \mathbf{n}(\mathbf{r}, t)=\overline{\mathbf{t}}(\mathbf{r}, t)$ on surface $A_{\mathbf{r}}^{t}$, 
where $\overline{\mathbf{u}}(\mathbf{r}, t)$ are the prescribed displacements on surface $A_{\mathbf{r}}^{u}, \overline{\mathbf{t}}$ are the prescribed tractions on surface, and $\mathbf{n}$ is the unit outward normal to the surface $A_{\mathbf{r}}^{t}$.

The total strain is the Green's strain

$\varepsilon(\mathbf{r}, t)=\frac{1}{2}\left[\nabla_{\mathbf{r}} \mathbf{u}(\mathbf{r}, t)+\left(\nabla_{\mathbf{r}} \mathbf{u}(\mathbf{r}, t)\right)^{T}\right]$

Assuming small deformation thermo-elastic-plasticity, the additive decomposition of total strain is applied as

$\varepsilon=\varepsilon_{e}+\varepsilon_{p}+\varepsilon_{t}$

where $\varepsilon_{e}, \varepsilon_{p}$ and $\varepsilon_{t}$ are the elastic, plastic and thermal strain, respectively.

The initial conditions are

$\mathbf{u}\left(\mathbf{r}, t_{0}\right)=\mathbf{u}^{0}(\mathbf{r})$,

$\varepsilon_{p}\left(\mathbf{r}, t_{0}\right)=\varepsilon_{p}^{0}(\mathbf{r})$,

$\varepsilon_{q}\left(\mathbf{r}, t_{0}\right)=\varepsilon_{q}^{0}(\mathbf{r})$

where $\varepsilon_{q}$ is the equivalent plastic strain, and $t_{0}$ is the time for the previous time increment.

\section{Finite Element Simulation}

Analytical prediction of the thermal and displacement fields for laser forming process is complex, as the relevant thermophysical properties, as well as the temperature, and displacements keep on changing. Therefore, numerical modeling can be more amenable and accurate for analyzing the laser forming process. In the present work, laser forming is simulated as sequentially coupled thermo-elasto-plastic analysis, using the commercially available Finite Element Software, ANSYS®. The temperature profile on the plate, as the beam traverses it, is obtained by appropriate thermal modeling and the results of which are given as input for the structural analysis.

ANSYS $®$ Parametric Design Language, a scripting language is used to do the programming. This allows for parametric programming, helpful in studying the effect of process parameters.

The problem considered here is a circular plate of radius $50 \mathrm{~mm}$ with a central hole of radius $6 \mathrm{~mm}$, shown in Fig. 2. The plate is clamped through the central hole. There is no loading applied on the plate and the self weight is ignored. The laser beam is traversed along the irradiation circle shown in Fig. 2. The process parameters considered are given in the table 1.

Table 1. Process parameters chosen for circle line heating

\begin{tabular}{|l|l|}
\hline Parameter & Value \\
\hline Power & $1200 \mathrm{~W}$ \\
\hline Beam Diameter & $12 \mathrm{~mm}$ \\
\hline Scanning Velocity & $15 \mathrm{~mm} / \mathrm{s}$ \\
\hline Absorption Coefficient & $0.68[11]$ \\
\hline Ambient temperature & $298 \mathrm{~K}$ \\
\hline Specimen thickness & $2 \mathrm{~mm}$ \\
\hline
\end{tabular}

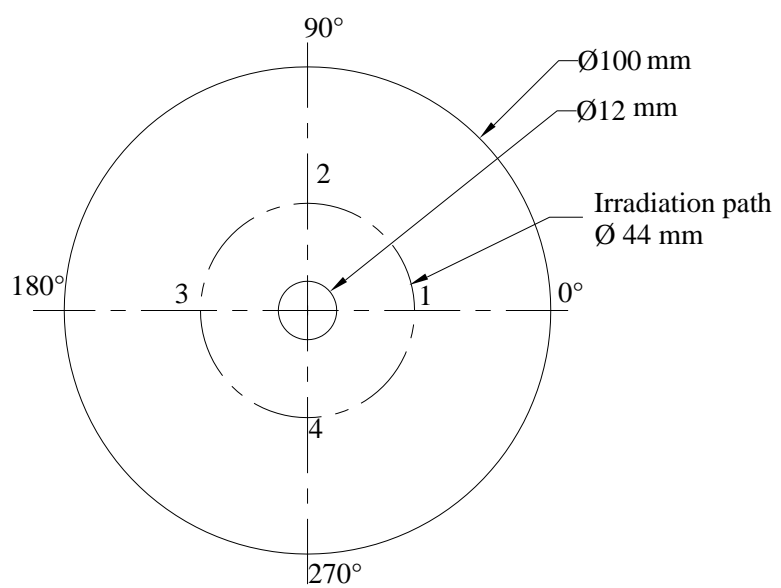

Figure 2. Schematic diagram showing the irradiation path 


\subsection{Modeling and moving the Heat Flux}

The thermal load is given in the form of heat flux that obeys a Gaussian distribution as illustrated in Eq. (5). The traversal of laser beam is modeled as a moving heat flux with small steps, of the order of 0.1 seconds. When $t=t_{0}$, where $t_{0}$ is the time at a given instant, the center of the heat flux is at the origin of a local coordinate system and the surrounding nodes which fall under the beam radius are selected, to which the heat flux, based on Eq. (5), is given as input. In the next time step, when $t=t_{0}+\Delta t$, where $\Delta t$ is the incremental time added to get the time at successive instants, the local coordinate system is moved to appropriate position along the irradiation path. The jumping of this heat flux is kept to a minimum so that it simulates continuous scanning. The total heating time depends on the relative motion between the sheet and the laser beam and is given as $t_{t o t}=2 \pi r_{i} / V$ where $V$ is the velocity of the beam traverse, called scanning speed and $r_{i}$ is the radius of the irradiation circle. From this, the heating time for every single load step is calculated as $\Delta t=t_{t o t} / n$ where $n$ is the number of load steps and $t_{t o t}$ is the total time of traverse. Hence, by controlling the total time of traverse and time of each load step, the velocity of traverse is controlled.

\subsection{Differential Density Meshing}

The model is meshed using the element SOLID70 for the thermal analysis. SOLID70 has a 3-D thermal conduction capability. The element has eight nodes with a single degree of freedom, temperature, at each node. The element is applicable to a 3-D, steady-state or transient thermal analysis. Convection or heat flux (but not both) and radiation may be input as surface loads at the element faces. Convection heat flux is positive out of the element; applied heat flux is positive into the element. The solution output associated with the element is the nodal temperatures included in the overall nodal solution.

The temperature gradient and the stress gradient around the laser traversing path are high and, therefore, require a denser mesh. However, maintaining higher mesh density throughout the plate increases the total number of degrees of freedom and computation time. Therefore, to reduce the large computation time, a coarser mesh is used in the remaining portion of the plate. The differential density meshing, as shown in Fig. 3, is achieved by direct generation of elements out of nodes, instead of starting with volume and discretizing into elements.

\subsection{Material Properties}

The plate is assumed to be of isotropic, elastic-perfectly plastic material. The material yield is based on the von Mises yield criterion. The material assumed is $\mathrm{AH} 36$. The temperature dependent thermo-mechanical properties, used in the present analysis, are taken from Zhang et al. (2004).

3.4 Structural Analysis

SOLID70 is replaced with SOLID45 for the 3-D modeling of solid structures. The element is defined by eight nodes, having three degrees of freedom at each node: translations in the nodal $\mathrm{x}-, \mathrm{y}$ - and z-directions. The result of the thermal analysis is given as the input for the structural analysis. The plate is clamped at the inner hole i.e., displacements and rotations at the inner surface of the central hole are constrained in the $\mathrm{x}-, \mathrm{y}$ - and $\mathrm{z}$-directions to arrest the rigid body motion. The stress strain curve at different temperature is included in the material properties. von Mises yield criterion is assumed.

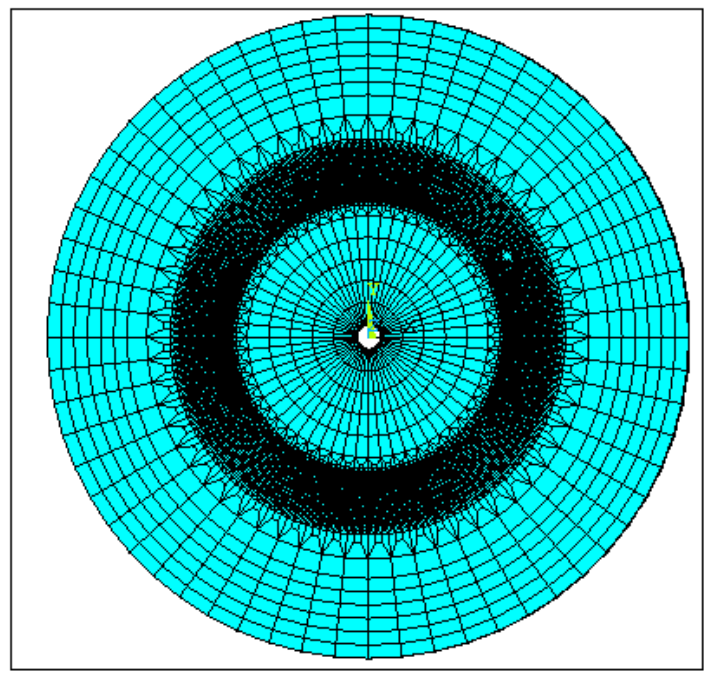

Figure 3. Differential density meshing 


\section{Results and Discussion}

Initially, single section and single pass irradiation of circular plate is studied, to identify the waviness pattern, presented in section 4.1, and then, discrete section and multi pass heating, with and without change of starting point in subsequent passes is investigated to eliminate or reduce the amount of waviness.

\subsection{Single Section Single Pass Heating}

\subsubsection{Transient temperature fields}

Fig. 4 shows the temperature distribution on the top surface. We observe a preheated zone ahead of the laser spot and a heated trail behind the laser spot because of the heat diffusion. Also it can be seen that as the beam passes over the plate it induces a steep temperature gradient across the thickness of the sheet, as shown in Fig. 5. Fig. 6 shows the transient temperature variation at a node located close to $90^{\circ}$ of the irradiation path, noted in Fig. 2, on the top surface and the same at the corresponding node on the bottom surface. It can be observed that there is difference in peak temperatures of nodes at top surface and bottom surface. Also, there is a delay with the bottom node, in reaching the peak temperature, due to heat diffusion. The difference in the peak temperatures on the top and bottom nodes, together with the associated delay, gives rise to an unequal bending moment along the top and bottom heating lines of the sheet, leading to its deformation.
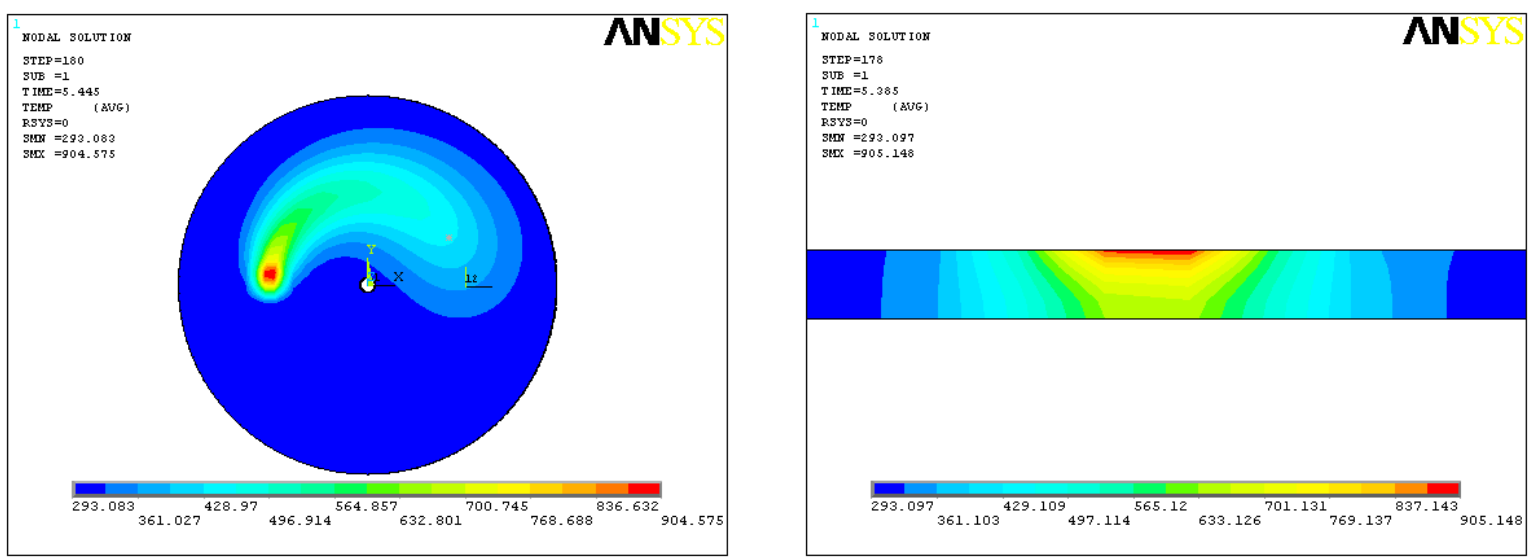

Figure 4. Temperature distribution on the top surface

Figure 5. Temperature distribution across the thickness

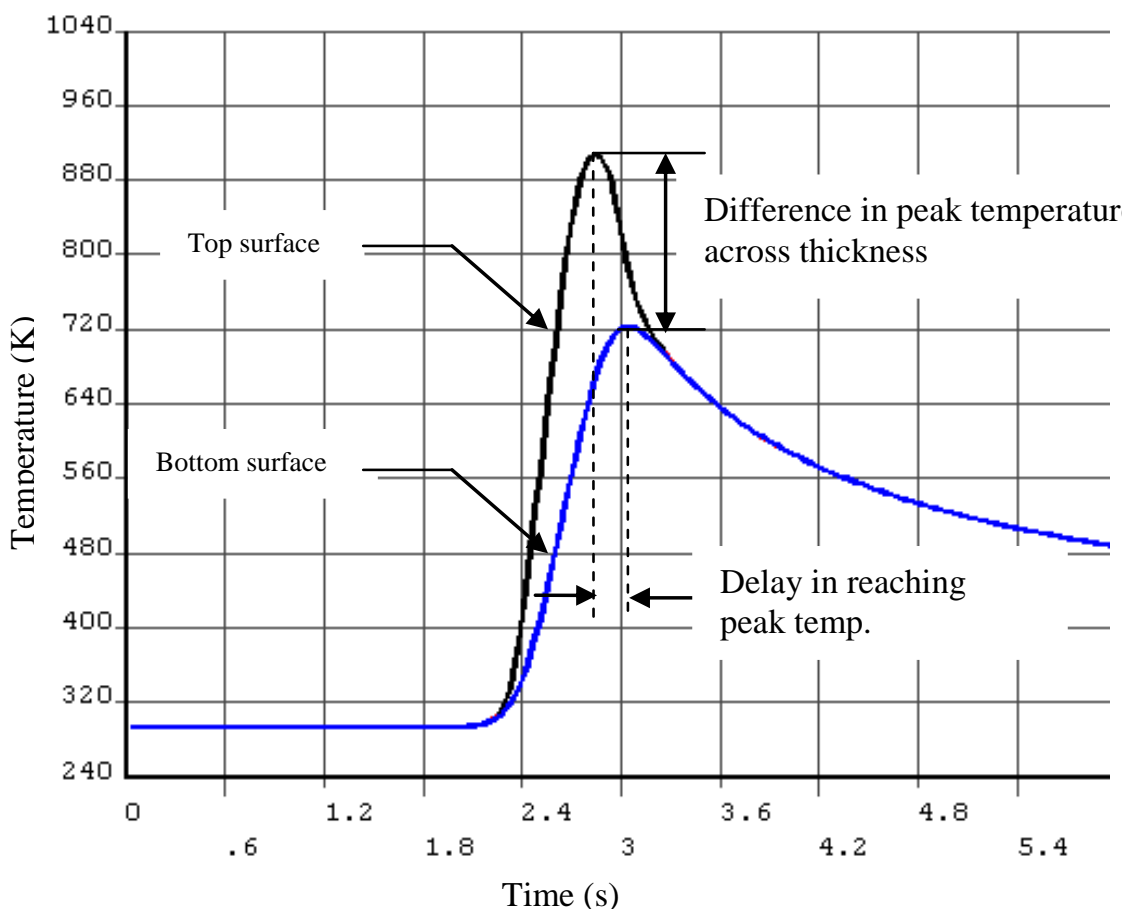

Figure 6. Temperatures at a node on top surface and the corresponding node at bottom surface 


\subsubsection{Displacement}

Fig. 7 shows the displacement of the sheet metal in the z-direction, after 1 pass of laser irradiation and the plate getting cooled down to the initial temperature. As can be seen from the Fig. 7, the final deformation of the plate is not uniform peripherally. The z-direction displacement of the nodes on the top surface at the outer circumference is shown in Fig. 8, as a function of angle from $0^{\circ}$ to $360^{\circ}$, as indicated in Fig. 2. In ideal case, it should be a horizontal straight line. However, as it can be seen from Fig. 8, there exists waviness, that may grow in subsequent passes and this is undesirable. In the following sections, attempts are made to eliminate this waviness by introducing discrete section-wise heating as well as by changing the starting points of irradiation in subsequent passes. Care is taken that heating pattern follows symmetry, thereby, reducing waviness.

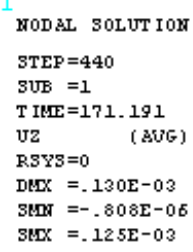

$\mathbf{N}$
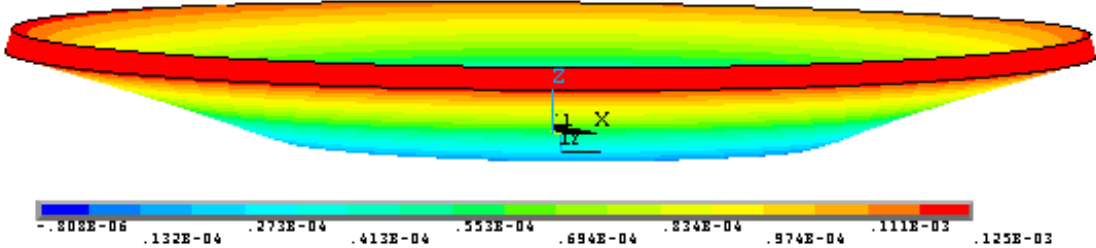

Figure 7. Displacement of the plate after 1 pass single section heating

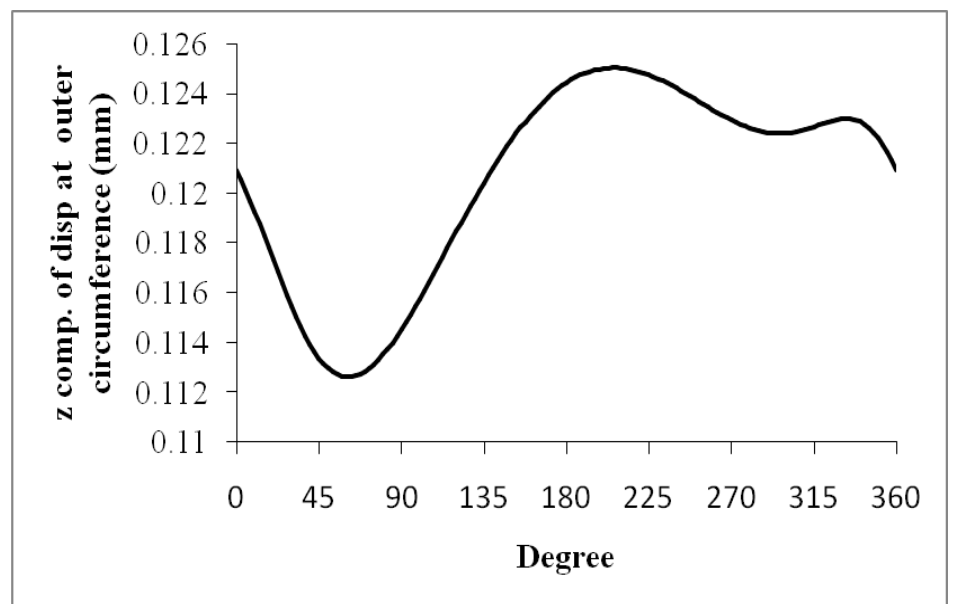

Figure 8. Outer circumferential waviness for 1 section 1 pass

\subsection{Discrete Section Heating}

In order to reduce the waviness, the laser traversing along the irradiation circle is done in discrete sections and in an order such that the symmetry is mostly maintained, as shown in Fig. 9. For, example, for 4 sector heating, section 1 is traversed first (from $0^{0}$ to $90^{\circ}$ ) and then, section 3 is traversed (from $180^{\circ}$ to $270^{\circ}$ ). Then similarly, sections 2 and 4 are traversed. In the second pass, the starting point is displaced at an angle of $90^{\circ}$ and the sequence followed is section $3\left(180^{\circ}\right.$ to $\left.270^{\circ}\right)$, section $1\left(0^{\circ}\right.$ to $\left.90^{\circ}\right)$, section 4 $\left(270^{\circ}\right.$ to $\left.360^{\circ}\right)$ and section $2\left(90^{\circ}\right.$ to $\left.180^{\circ}\right)$. Table 2 gives the sequence of heating for four pass traversal by laser beam along the irradiation circle. The plate is allowed to cool for 120 seconds to prevent the accumulation of heat by continuous irradiation, such that the temperature of the plate does not exceed the melting point of the plate material. 


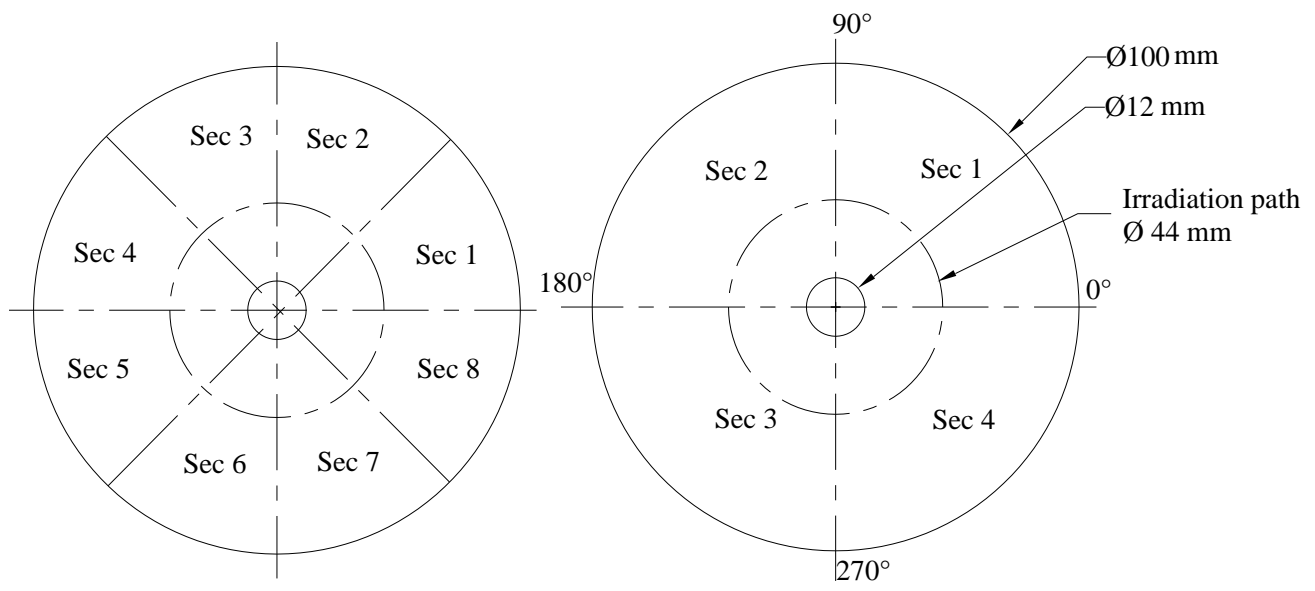

Figure 9. Discrete sections of heating

Heating of more than eight sectors is not attempted because the laser beam traversing requires some time along its travel to reach a steady maximum temperature, which could yield maximum bending for that velocity. If the sector is too small, time is not sufficient to reach that maximum steady temperature and hence the angle of bend will be less.

Table 2. Sequence of laser beam traversing along the irradiation path

\begin{tabular}{|c|c|}
\hline No. of Sections & Sequence \\
\hline $1(\mathrm{SS})$ & 1-2-3-4 - cooling - 1-2-3-4 - cooling - 1-2-3-4 - cooling - 1-2-3-4 - cooling \\
\hline $4(\mathrm{SS})$ & 1-3-2-4 - cooling -1-3-2-4 - cooling-1-3-2-4 - cooling-1-3-2-4 - cooling \\
\hline $8(\mathrm{SS})$ & $\begin{array}{c}\text { 1-5-3-7-2-6-4-8 - cooling-1-5-3-7-2-6-4-8 - cooling-1-5-3-7-2-6-4-8 - } \\
\text { cooling - 1-5-3-7-2-6-4-8 - cooling }\end{array}$ \\
\hline $1(\mathrm{DS})$ & 1-2-3-4- cooling - 2-3-4-1 - cooling - 3-4-1-2 - cooling - 4-1-2-3 - cooling \\
\hline $4(\mathrm{DS})$ & 1-3-2-4 - cooling - 2-4-3-1 - cooling - 3-1-2-4 - cooling - 4-2-1-3 - cooling \\
\hline $8(\mathrm{DS})$ & $\begin{aligned} \text { 1-5-3-7-2-6-4-8 - } & \text { cooling - 3-7-5-1-4-8-6-2- cooling - 5-1-7-3-6-2-8-4- } \\
& \text { cooling - 7-3-1-5-8-4-2-6 - cooling }\end{aligned}$ \\
\hline
\end{tabular}

The waviness pattern is studied for discrete section-wise heating for 4 and 8 sections, for 4 passes with same starting point (SS) and different starting points (DS) in the subsequent passes.

\subsubsection{Transient temperature fields}

Fig. 10 shows the maximum temperature experienced by the nodes at irradiation circle as well as the $\mathrm{z}$ component of displacement at the outer circumference for 4 passes. For single section heating the temperature reaches a steady maximum after $45^{\circ}$ and remains the same until $270^{\circ}$, before showing a rise in the fourth quadrant, due to the diffused heat from the starting point. This results in the maximum waviness, as can be seen from table 3 . For discrete section heating, as in the case of 8 section heating, the $\mathrm{T}_{\max }$, is not steady as the traversing point is interrupted, and therefore requires time to reach steady maximum temperature on every such interruption. However, this pattern of $T_{\max }$ reduces the valley $\left(\mathrm{R}_{\mathrm{v}}\right)$ and peak $\left(\mathrm{R}_{\mathrm{p}}\right)$ along the waviness curve, thereby ensuring a more uniform bending. Therefore, discrete section heating can be a strategy to reduce waviness in the final deformed shape. 


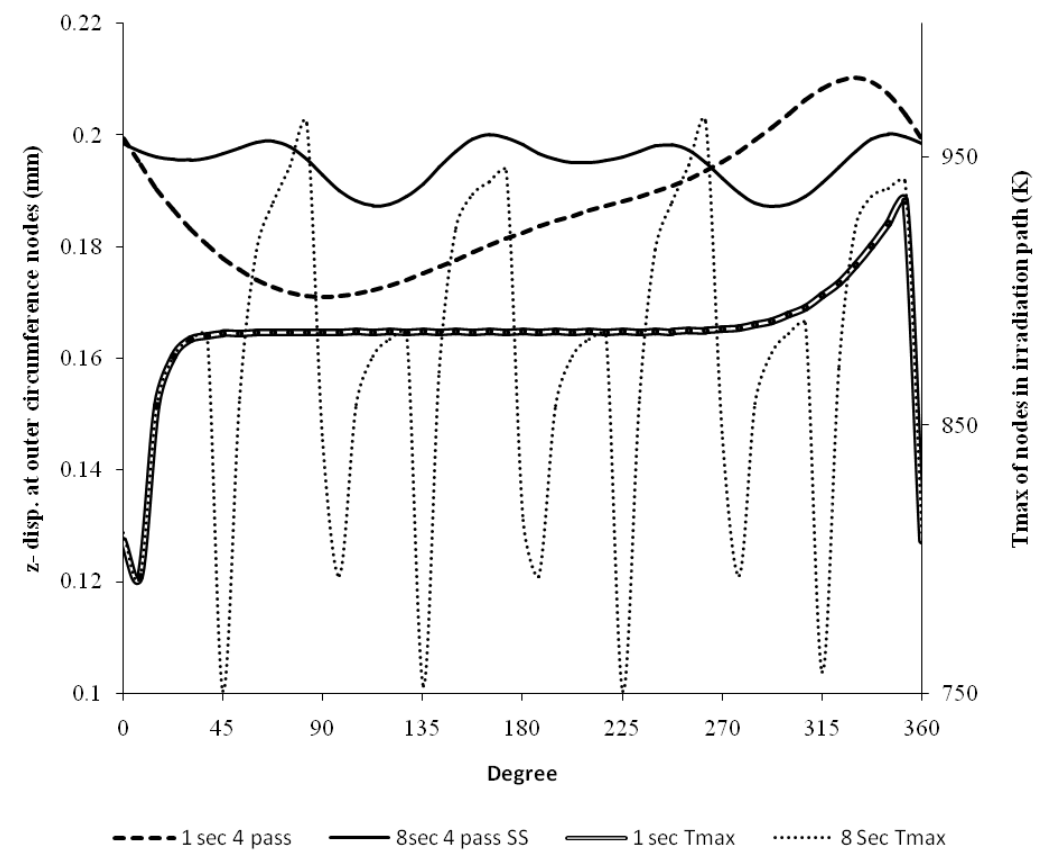

Figure 10. $\mathrm{T}_{\text {max }}$ at nodes of irradiation path and corresponding $\mathrm{z}$ disp. at outer circumference nodes

\subsubsection{Effect on bending angle}

It is observed from Fig. 11 that for 1 pass heating, average value of $\mathrm{z}$ component of displacement at outer circumferential nodes reduces with increase in number of sections. However, for subsequent number of passes (2, 3 and 4$)$, the values show an increasing trend with number of sections, for same starting (SS) point as well as different starting (DS) point heating, as shown in Figs. 11 (a) and (b) respectively. This can be attributed to the fact that during the first pass the plastic strain caused by sectional heating is less compared to the single section heating. However, in the subsequent passes, the stress builds up over the residual stress generated in the previous passes to cause more plastic strain compared to single section heating.

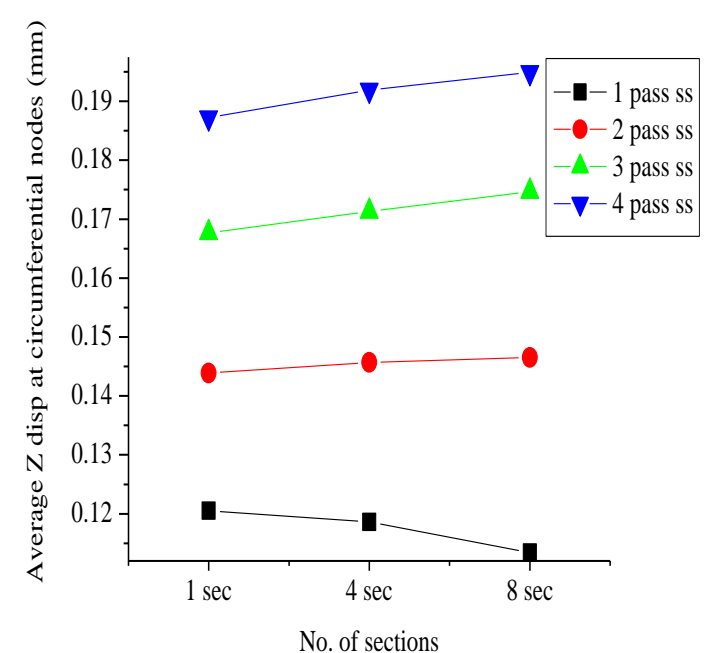

(a) Same starting point

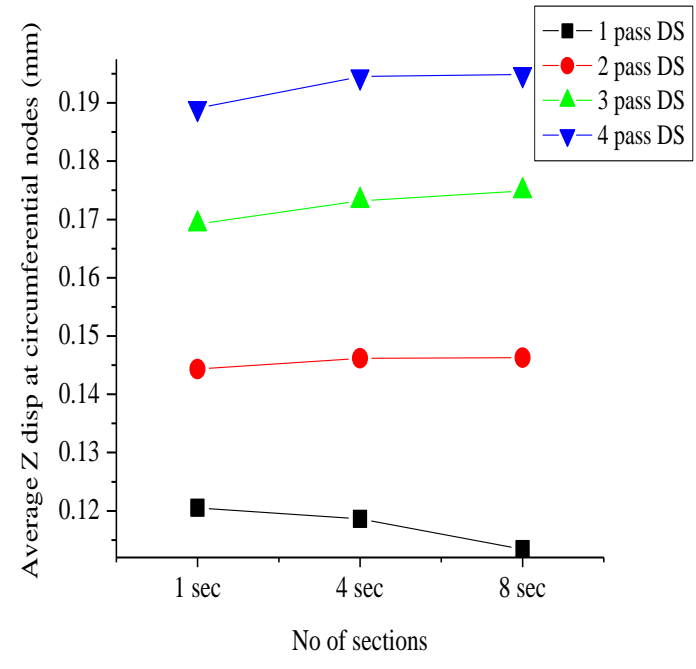

(b) Different starting point

Figure 11. Average $\mathrm{z}$ component of displacement at circumferential nodes

\subsubsection{Effect on waviness}

The waviness is calculated by waviness parameters (defined identical to roughness parameters and illustrated in Fig. 12) and the computed results are given in Tables $3-6$ for the cases listed in Table 2. 


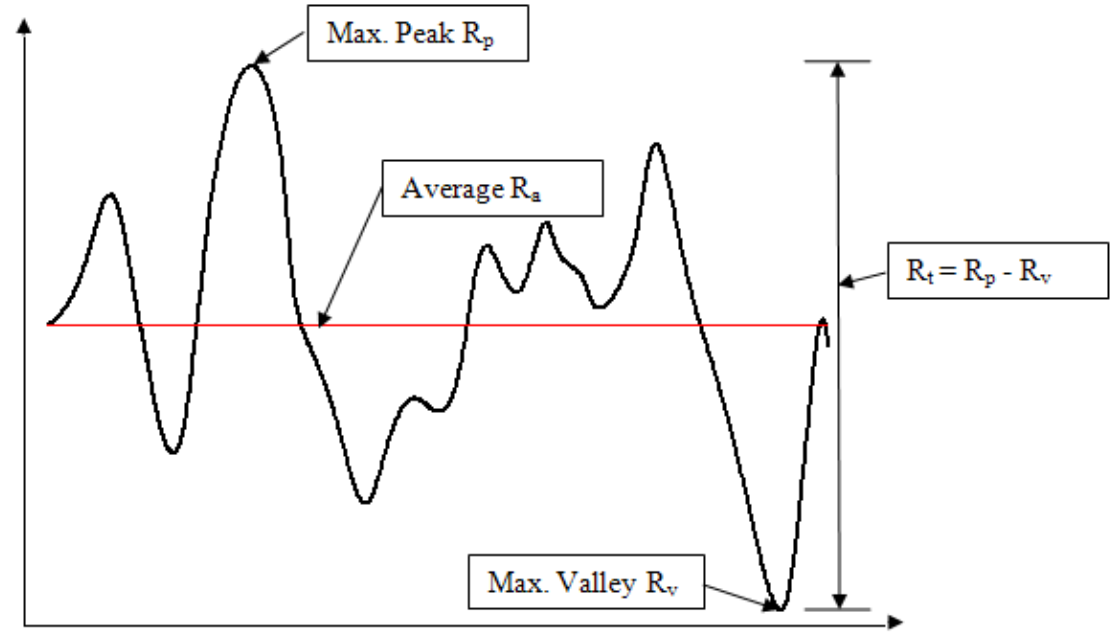

Figure 12. Waviness parameters

Table 3. Measure of waviness for cases of section-wise heating after 1 pass

\begin{tabular}{|c|c|c|c|}
\hline Parameter & 1 sec 1 pass & 4 sec 1 pass & 8 sec 1 pass \\
\hline$R a(\mathbf{m m})$ & $3.502 \mathrm{E}-03$ & $2.274 \mathrm{E}-03$ & $1.462 \mathrm{E}-03$ \\
\hline $\mathrm{Rq}(\mathbf{m m})$ & $4.039 \mathrm{E}-03$ & $2.602 \mathrm{E}-03$ & $1.747 \mathrm{E}-03$ \\
\hline $\mathrm{Rv}(\mathbf{m m})$ & $-7.902 \mathrm{E}-03$ & $-5.003 \mathrm{E}-03$ & $-2.828 \mathrm{E}-03$ \\
\hline $\mathrm{Rp}(\mathbf{m m})$ & $4.518 \mathrm{E}-03$ & $3.747 \mathrm{E}-03$ & $3.302 \mathrm{E}-03$ \\
\hline $\mathrm{Rt}(\mathbf{m m})$ & $1.242 \mathrm{E}-02$ & $8.750 \mathrm{E}-03$ & $6.130 \mathrm{E}-03$ \\
\hline$R_{\mathrm{Ku}}$ & $-8.798 \mathrm{E}-01$ & $-1.090 \mathrm{E}+00$ & $-9.278 \mathrm{E}-01$ \\
\hline
\end{tabular}

From Table 3, it may be observed that average waviness $R_{a}$ is reduced for 4 section and 8 section heating. The RMS value of waviness, $R_{q}$ is a measure of deviation from the mean value, $R_{a}$, and $R_{t}$ is the height of the waviness, $\left(R_{p}-R_{v}\right)$ both are minimum with 8 -section heating; $R_{p}$ and $R_{v}$ represent the peak and valley of the waviness.

Fig. 13 (a) shows that the waviness average $R_{a}$, is lower for discrete sections heating compared to the single section heating for all the number of passes considered. Column 3 and 4 of Table 4, 5 and 6 confirms that other waviness parameters for 4 section and 8 section heating, also showing considerable decline, compared to single section heating.

Table 4. Measure of waviness for cases of section-wise heating after 2 pass

\begin{tabular}{|c|c|c|c|c|c|c|}
\hline & $\begin{array}{c}1 \text { sec } 2 \text { pass } \\
\text { Parameter }\end{array}$ & $\begin{array}{c}\text { 4 sec 2pass } \\
\text { SS }(\mathbf{m m})\end{array}$ & $\begin{array}{c}\text { 8 sec } 2 \text { pass } \\
\text { SS }(\mathbf{m m})\end{array}$ & $\begin{array}{c}1 \text { sec } 2 \text { pass } \\
\text { DS }(\mathbf{m m})\end{array}$ & $\begin{array}{c}\text { 4 sec } 2 \text { pass } \\
\text { DS }(\mathbf{m m})\end{array}$ & $\begin{array}{c}\text { 8 sec } 2 \text { pass } \\
\text { DS }(\mathbf{m m})\end{array}$ \\
\hline $\mathrm{Ra}(\mathbf{m m})$ & $6.1627 \mathrm{E}-03$ & $5.7230 \mathrm{E}-03$ & $2.077 \mathrm{E}-03$ & $5.151 \mathrm{E}-03$ & $1.9837 \mathrm{E}-03$ & $2.080 \mathrm{E}-03$ \\
\hline $\mathrm{Rq}(\mathbf{m m})$ & $7.290 \mathrm{E}-03$ & $6.402 \mathrm{E}-03$ & $2.539 \mathrm{E}-03$ & $5.932 \mathrm{E}-03$ & $2.411 \mathrm{E}-03$ & $2.621 \mathrm{E}-03$ \\
\hline $\mathrm{Rv}(\mathbf{m m})$ & $-1.123 \mathrm{E}-02$ & $-9.263 \mathrm{E}-03$ & $-4.695 \mathrm{E}-03$ & $-7.729 \mathrm{E}-03$ & $-3.6806 \mathrm{E}-03$ & $-6.020 \mathrm{E}-03$ \\
\hline $\mathrm{Rp}(\mathbf{m m})$ & $1.292 \mathrm{E}-02$ & $1.079 \mathrm{E}-02$ & $4.645 \mathrm{E}-03$ & $1.041 \mathrm{E}-02$ & $4.5794 \mathrm{E}-03$ & $3.850 \mathrm{E}-03$ \\
\hline $\mathrm{Rt}(\mathbf{m m})$ & $2.415 \mathrm{E}-02$ & $2.005 \mathrm{E}-02$ & $9.340 \mathrm{E}-03$ & $1.814 \mathrm{E}-02$ & $8.2600 \mathrm{E}-03$ & $9.870 \mathrm{E}-03$ \\
\hline $\mathrm{R}_{\mathrm{Ku}}$ & $-1.051 \mathrm{E}+00$ & $-1.405 \mathrm{E}+00$ & $-7.992 \mathrm{E}-01$ & $-1.197 \mathrm{E}+00$ & $-9.021 \mathrm{E}-01$ & $-3.164 \mathrm{E}-01$ \\
\hline
\end{tabular}

Table 5. Measure of waviness for cases of section-wise heating after 3 pass

\begin{tabular}{|c|c|c|c|c|c|c|}
\hline Parameter & $\begin{array}{c}1 \text { sec } 3 \text { pass } \\
\text { SS }(\mathrm{mm})\end{array}$ & $\begin{array}{c}4 \text { sec 3pass } \\
\text { SS }(\mathrm{mm})\end{array}$ & $\begin{array}{c}8 \text { sec } 3 \text { pass } \\
\text { SS }(\mathrm{mm})\end{array}$ & $\begin{array}{c}1 \text { sec } 3 \text { pass } \\
\text { DS }(\mathrm{mm})\end{array}$ & $\begin{array}{c}4 \text { sec } 3 \text { pass } \\
\text { DS }(\mathrm{mm})\end{array}$ & $\begin{array}{c}8 \text { sec } 3 \text { pass } \\
\text { DS }(\mathrm{mm})\end{array}$ \\
\hline $\mathrm{Ra}(\mathbf{m m})$ & 8.3204E-03 & $7.5161 \mathrm{E}-03$ & $2.7043 \mathrm{E}-03$ & $3.4372 \mathrm{E}-03$ & $3.6940 \mathrm{E}-03$ & $2.2555 \mathrm{E}-03$ \\
\hline $\mathrm{Rq}(\mathrm{I}$ & 9.8525 & 8.3470 & 3.3124 & 4.222 & $4.0925 \mathrm{~F}$ & 2.5987 \\
\hline $\mathrm{Rv}($ & -1.3679 & $-1.1062 \mathrm{~F}$ & -6.4178 & -6.2945 & $-5.1496 \mathrm{~B}$ & $-4.6346 \mathrm{E}-03$ \\
\hline $\mathrm{Rp}($ & $1.8361 \mathrm{E}-02$ & $1.3928 \mathrm{E}-02$ & $4.8322 \mathrm{E}-03$ & $8.0355 \mathrm{E}-03$ & $6.6204 \mathrm{E}-03$ & $4.5654 \mathrm{E}-03$ \\
\hline Rt (I & 3.204 & $2.4990 \mathrm{E}-02$ & $1.1250 \mathrm{E}-02$ & 1.43 & $1.1770 \mathrm{E}-02$ & $9.2000 \mathrm{E}-03$ \\
\hline $\mathrm{R}_{\mathrm{Ku}}$ & $-1.0118 \mathrm{E}+00$ & $-1.4664 \mathrm{E}+00$ & $-7.8483 \mathrm{E}-01$ & $-7.7840 \mathrm{E}-01$ & $-1.4786 \mathrm{E}+00$ & $-1.1630 \mathrm{E}+00$ \\
\hline
\end{tabular}


Table 6. Measure of waviness for cases of section-wise heating after 4 pass

\begin{tabular}{|c|c|r|c|c|c|c|}
\hline Parameter & $\begin{array}{c}\text { 1 sec 4 pass } \\
\text { SS }(\mathbf{m m})\end{array}$ & $\begin{array}{c}\text { 4 sec 4 pass } \\
\text { SS }(\mathbf{m m})\end{array}$ & $\begin{array}{c}\text { 8 sec 4 pass } \\
\text { SS }(\mathbf{m m})\end{array}$ & $\begin{array}{c}\text { 1 sec 4 pass } \\
\text { DS }(\mathbf{m m})\end{array}$ & $\begin{array}{c}\text { 4 sec 4 pass } \\
\text { DS }(\mathbf{m m})\end{array}$ & $\begin{array}{c}\text { 8 sec 4 pass } \\
\text { DS }(\mathbf{m m})\end{array}$ \\
\hline $\mathrm{Ra}(\mathbf{m m})$ & $1.0338 \mathrm{E}-02$ & $9.6449 \mathrm{E}-03$ & $3.2633 \mathrm{E}-03$ & $1.7992 \mathrm{E}-03$ & $2.3003 \mathrm{E}-03$ & $2.6823 \mathrm{E}-03$ \\
\hline $\mathrm{Rq}(\mathbf{m m})$ & $1.2211 \mathrm{E}-02$ & $1.0686 \mathrm{E}-02$ & $3.9306 \mathrm{E}-03$ & $6.2557 \mathrm{E}-03$ & $2.7650 \mathrm{E}-03$ & $3.1264 \mathrm{E}-03$ \\
\hline $\mathrm{Rv}(\mathbf{m m})$ & $-1.6231 \mathrm{E}-02$ & $-1.3573 \mathrm{E}-02$ & $-7.6756 \mathrm{E}-03$ & $-3.7678 \mathrm{E}-03$ & $-4.3756 \mathrm{E}-03$ & $-5.8885 \mathrm{E}-03$ \\
\hline $\mathrm{Rp}(\mathbf{m m})$ & $2.3029 \mathrm{E}-02$ & $1.7707 \mathrm{E}-02$ & $5.2944 \mathrm{E}-03$ & $4.8522 \mathrm{E}-03$ & $4.6944 \mathrm{E}-03$ & $4.7415 \mathrm{E}-03$ \\
\hline $\mathrm{Rt}(\mathbf{m m})$ & $3.9260 \mathrm{E}-02$ & $3.1280 \mathrm{E}-02$ & $1.2970 \mathrm{E}-02$ & $8.6200 \mathrm{E}-03$ & $9.0700 \mathrm{E}-03$ & $1.0630 \mathrm{E}-02$ \\
\hline $\mathrm{R}_{\mathrm{Ku}}$ & $-1.0121 \mathrm{E}+00$ & $-1.4733 \mathrm{E}+00$ & $-7.7851 \mathrm{E}-01$ & $-4.4441 \mathrm{E}-01$ & $-9.7995 \mathrm{E}-01$ & $-1.0863 \mathrm{E}+00$ \\
\hline
\end{tabular}

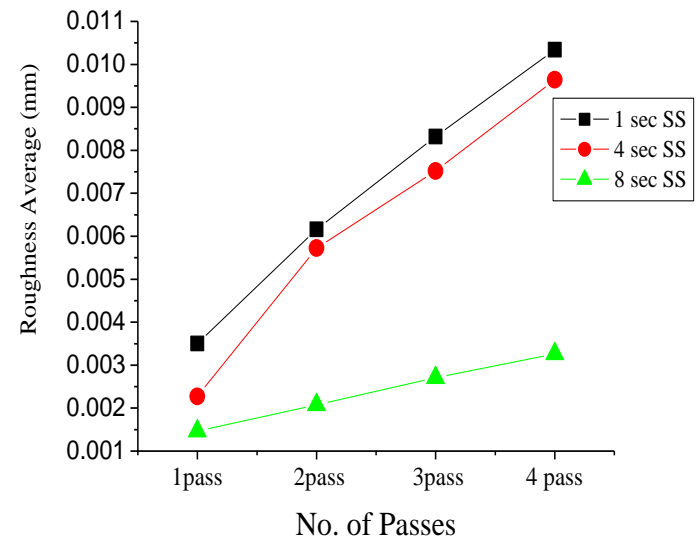

(a) Same starting point (SS)

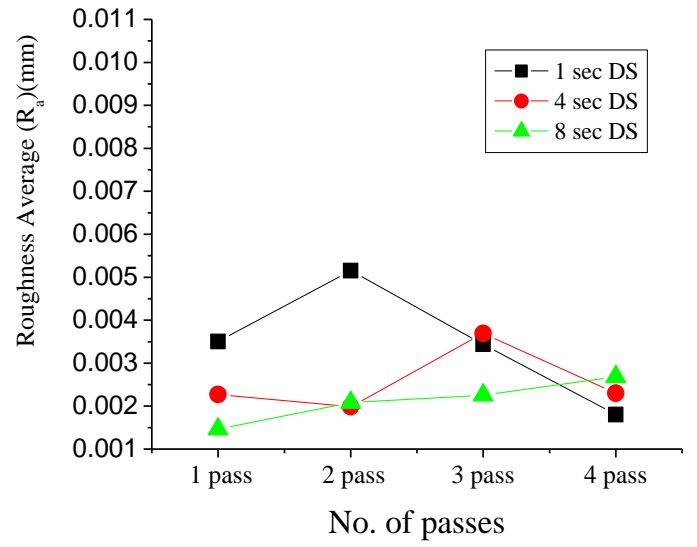

(b) Same starting point (SS)

Figure 13. Roughness average of displacement at circumferential nodes

Fig. 14 shows the $\mathrm{z}$ component of displacement at the outer circumferential nodes for single section and discrete sections heating after 4 passes, for the cases of same starting point (SS) and different starting point (DS). The average waviness after 4 passes for different starting point shows lower values than those for same starting point cases, as can be seen from Fig. 13 (a) and (b). Also, Fig. 13 (b) shows that, the change of starting point in the subsequent passes tries to compliment the waviness generated in the previous passes and hence after 4 passes, it reaches to a minimum, whereas in same starting point cases, the waviness pattern remains almost same throughout the number of passes, and further, $R_{p}, R_{v}$ and $R_{t}$ increases.

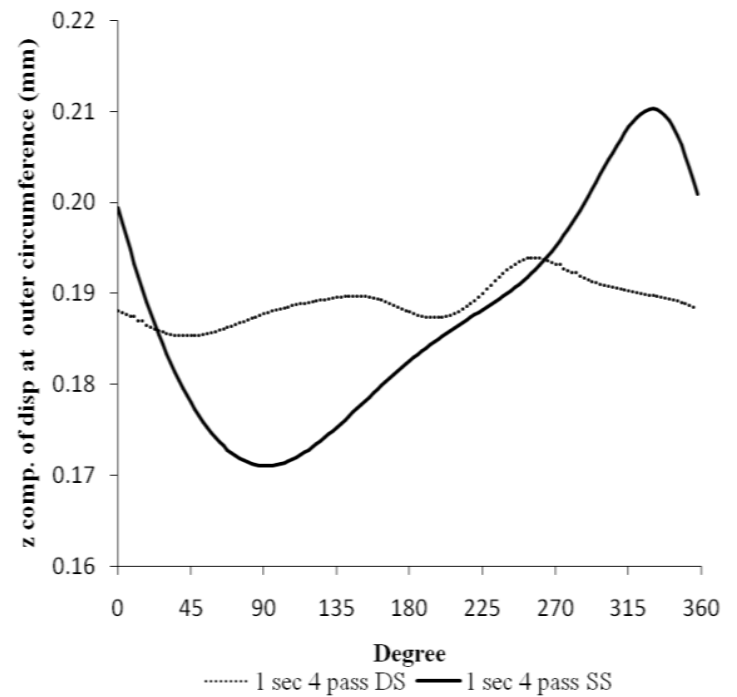

(a) 1 section

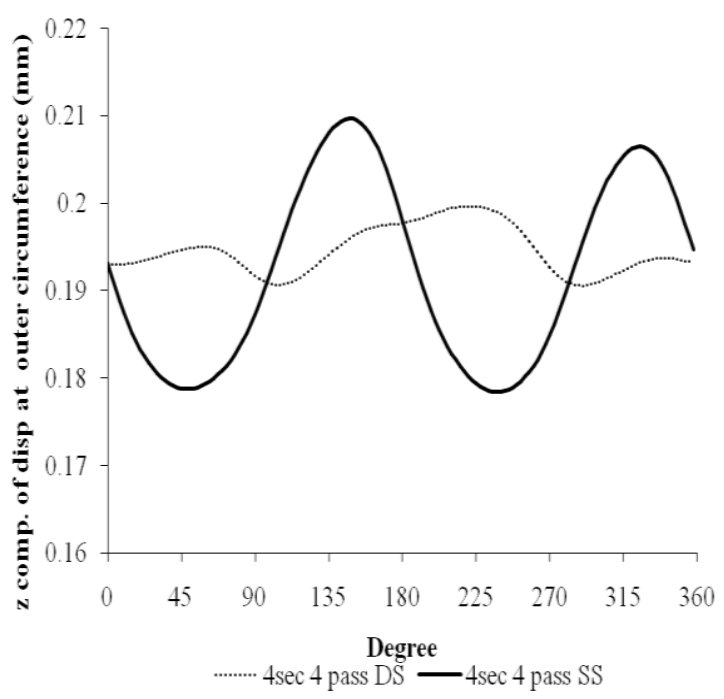

(b) 4 section

Figure 14. Effect of change of starting point of traverse 
Therefore, it may be concluded that changing the starting point in the subsequent passes could also well be another strategy to reduce the waviness in the final required shape. However, positioning the subsequent starting points may depend on the irradiation path and the final shape required and requires further investigation, which requires further investigation.

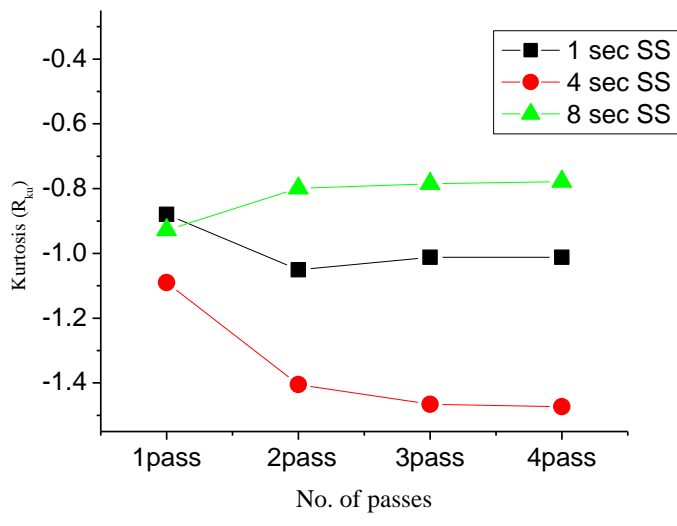

(a) Same starting point

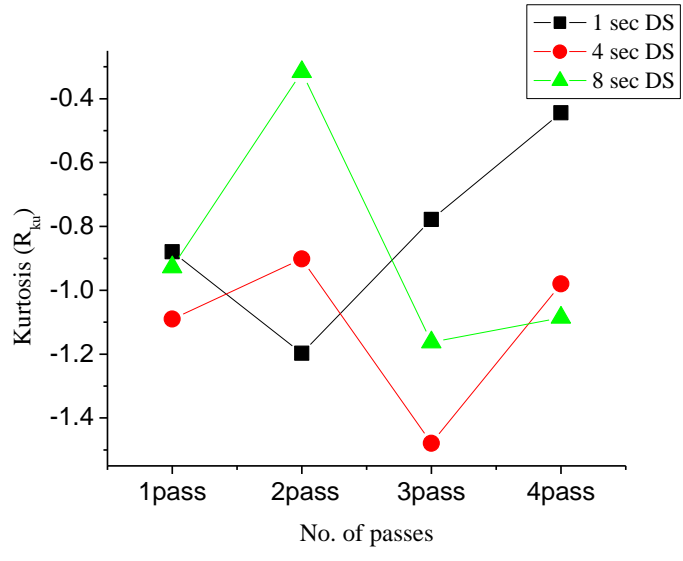

(b) Different starting point

Figure 15. Kurtosis of displacement at circumferential nodes

Kurtosis is the measure of flatness or peakedness of distribution and if $\mathrm{R}_{\mathrm{ku}}$ is greater than 3 , the distribution is said to be peaked and if it is less than 3, it is said to be flat. Considering our case, the distribution should be flat as every node on the circumference is expected to have uniform displacement. Fig. 15 (a) \& (b) shows the kurtosis of z displacement of circumferential nodes. For the same starting point, 8 sections heating and for different starting points, single section heating with $90^{\circ}$ phase difference, yields more flatter distribution.

Hence, it may be concluded, that waviness, which occurs with the circular heating of plates for bending, can be reduced with multiple section heating choosing diametrically opposite sectors, as well as by appropriately changing the starting points of subsequent passes.

\section{Conclusions}

A 3-D numerical simulation model is developed and investigation of the laser bending process for a circular plate is performed. The discrete section heating, tried in place of continuous heating, and change of the starting points in subsequent traversing are attempted and their effects are reported. The eight section heating and single section heating with $90^{\circ}$ phase shift in the starting point of subsequent traversing, shows considerable reduction in waviness. It can be inferred that short section symmetrical irradiation, accompanied by appropriate switching of starting points, can reduce waviness to a great extent.

\section{Nomenclature}

$\begin{array}{ll}A & \text { Absorptivity } \\ A_{\mathrm{r}}^{u} & \text { Surface domain }\left(\mathrm{m}^{2}\right) \\ \boldsymbol{b} & \text { Body force }(\mathrm{N}) \\ c & \text { Specific heat }(\mathrm{J} / \mathrm{kgK}) \\ h & \text { Heat transfer coefficient }\left(\mathrm{W} / \mathrm{m}^{2} \mathrm{~K}\right) \\ h_{\text {comb }} & \text { Combined heat transfer coefficient for radiation and convection }\left(\mathrm{W} / \mathrm{m}^{2} \mathrm{~K}\right) \\ I & \text { Heat flux distribution }\left(\mathrm{W} / \mathrm{m}^{2}\right) \\ K & \text { Thermal conductivity }\left(\mathrm{W} / \mathrm{mK}^{2}\right) \\ n & \text { Number of load steps } \\ \boldsymbol{n} & \text { Unit outward normal to the surface } \\ P & \text { Laser power }(\mathrm{W}) \\ q_{\text {conv }} & \text { Convective heat flux }\left(\mathrm{W} / \mathrm{m}^{2}\right) \\ q_{\text {rad }} & \text { Radiant heat flux }\left(\mathrm{W} / \mathrm{m}^{2}\right)\end{array}$




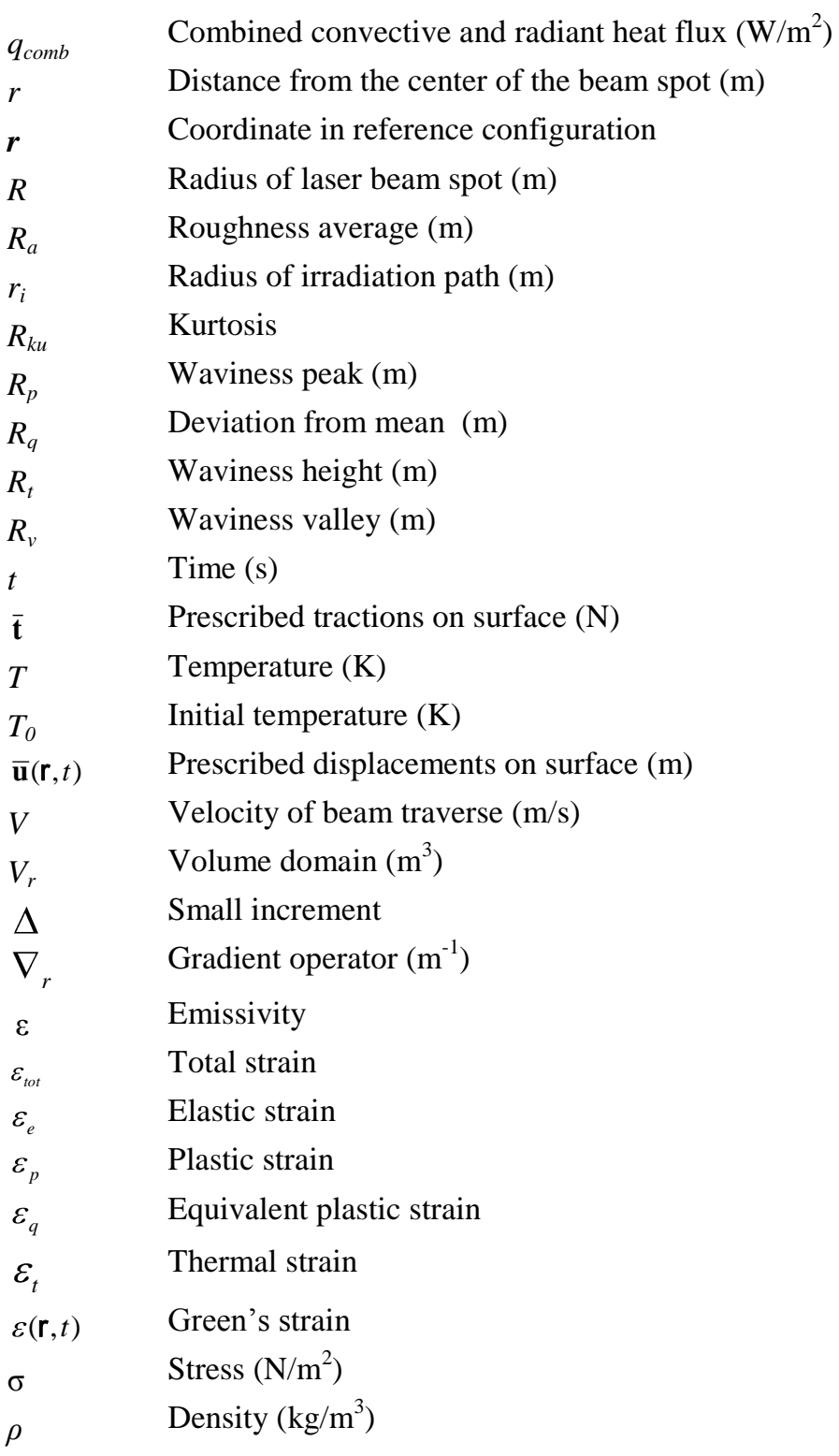

\section{References}

Chen D., Wu S. and Li M., 2004. Deformation behaviours of laser curve bending of sheet metals, Journal of Materials Processing Technology, Vol. 148, pp. 30-34.

Dearden G. and Edwardson S.P., 2003.Some recent developments in two and three dimensional laser forming for macro and micro applications", Journal of Optics A: Pure Applied Optics, pp. S8 -S15.

Edwardson S.P., Dearden G., French P., Watkins K.G., 2003. Laser forming of metal laminate composite material, paper 107, ICALEO, Jacksonville, FI, USA, Oct 13-16.

Edwardson S. P., Watkins K. G., Dearden G. and Magee J., 2001. 3D Laser forming of saddle shapes, Proceedings of the $3^{\text {rd }}$ International Conference on Laser Assisted Net Shaping (LANE) Erlangen, 28 -31, pp.559 - 568.

Hennige T., 2000. Development of irradiation strategies for 3D-laser forming, Journal of Materials Processing Technology, Vol. 103 , pp. 102-108.

Hu Z., Kovacevic R., Labudovic M., 2002. Experimental and numerical modeling of buckling instability of laser sheet forming, International Journal of Machine Tools and Manufacture, Vol. 42, pp. 1427-1349.

Ji Z. and Wu S., 1998. FEM simulation of temperature field during the laser forming of sheet metal, Journal of Material Processing Technology, Vol. 74, pp. 89-95.

Kim J. and Na S. J., 2003.Development of irradiation strategies for free curve laser forming, Optics and Laser Technology, Vol. 35, pp. 605-611. 
Kyrsandi An. K., Kermanidis Th.B., and Pantelakis Sp.G., 2000. An analytical model for the prediction of distortions caused by the laser forming process, Journal of Material Processing Technology, Vol. 104, pp. 94-102.

Ojedaa C.V. and Grez J.R., 2009. Bending of stainless steel thin sheets by a raster scanned low power CO2 laser, Journal of Materials Processing Technology, Vol. 209, pp.2641-2647.

Silve S., 2007. Laser forming: non contact metal bending offers silver smithing potential, GZ Art and Design, (2007)/1, pp. 78-79

Vollertsen F. and Holtzer G., 1994. Laser beam forming - fundamentals and possible applications, VDI-Z, 136 (1:2), pp. $35-38$

Yu G., Masubuchi K., Maekawa T. and Patrikalakis N. M., 2001. FEM simulation of laser forming of metal plates, Journal of Manufacturing Science and Engineering, Vol. 123, pp. $405-410$.

Zhang L., Reutzel E.W. and Michaleris P., 2004. Finite element modeling discretization requirements for the laser forming process, International Journal of Material Sciences, 46, pp. 623-637.

Zhang X. R., Chen G. and Xu X., 2002. Numerical simulation of pulsed laser bending, Journal of Applied Mechanics, Vol. 69, pp. 254- 260 .

Biographical notes

K. Venkadeshwaran is currently a Research Scholar in School of Laser Science \& Engineering, Jadavpur University, Kolkata, India. He completed his graduation in Mechanical Engineering from Government college of Engineering, Tirunelveli, India in 2001 and his post graduation in Industrial Engineering at Kumaraguru College of Engineering, Coimbatore, India in 2002. His research interest includes finite element modeling and laser processing of materials.

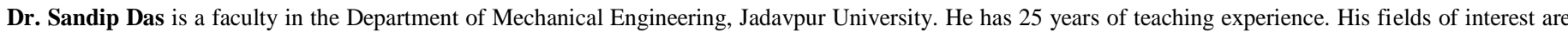

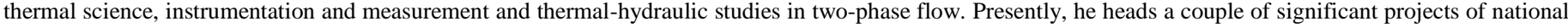
importance in the field of simulation of accident conditions in nuclear power plants.

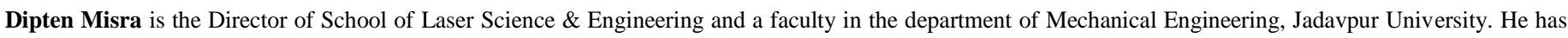
25 years of teaching experience. His research interests are heat and mass transfer, computational fluid dynamics and laser processing of materials.

Received January 2010

Accepted March 2010

Final acceptance in revised form May 2010 